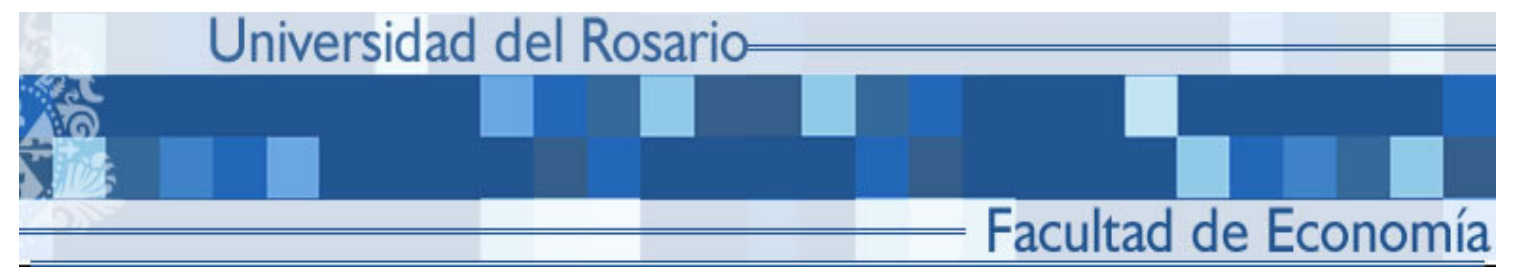

BODY MASS INDEX AS A STANDARD OF LIVING MEASURE: A DIFFERENT INTERPRETATION FOR THE CASE OF COLOMBIA.

Luis Fernando Gamboa

Nohora Forero 


\title{
Body Mass Index as a Standard of Living Measure: a different interpretation for the case of Colombia*
}

\author{
Luis Fernando Gamboa \\ Department of Economics \\ Universidad del Rosario \\ Casa Pedro Fermín \\ Address: Calle 14 No 4-69 \\ Phone: 2970200 ext 631,619 \\ Fax: 3445763 \\ Bogotá-Colombia \\ E-mail:1fgamboa@urosario.edu.co \\ Nohora Forero Ramírez \\ Department of Economics \\ Universidad del Rosario \\ Casa Pedro Fermín \\ Address: Calle 14 No 4-69 \\ Phone: 2970200 ext 645 \\ Fax: 3445763 \\ Bogotá-Colombia \\ E-mail: nyforero@urosario.edu.co
}

\begin{abstract}
We analyze the Body Mass Index (BMI) in a distinct way of its traditional use and it lets us use it as a proxy of standard of living for the case of Colombia. Our approach is focused on studying how far the people are from the normal range and not on the score of each one and this lets us to treat equally extreme cases as severe thinness and obesity. We use a probabilistic model (Ordered Probit) that evaluates the probability of being within the normal range or another level. We found that socioeconomic variables have a significant effect on the dependent variable and that there are no linear effects. Besides, people with difficulties for walking and adults have less probability of having a normal BMI.
\end{abstract}

Keywords: Standard of Living, Body Mass Index, Overweight.

JEL Classification: C35, D63, I19

\footnotetext{
* We acknowledge the comments and suggestions of Luis Eduardo Fajardo, Danielken Molina, Ana Vega, and the participants of the department of Economics Seminar. We also thank to Macro International-DHS and Profamilia for access to data, and Universidad del Rosario (FIUR) for financial support. Corresponding author: Luis Fernando Gamboa.
} 


\section{Introduction}

There has been a worldwide concern about obesity and severe thinness during the last decades. Although these situations are equally undesirable, most of the efforts focus on only one of them. In this document, we want to determine if the Body Mass Index -BMI hereafter, could be associated with an alternative measure of standard of living. Although traditional studies on standard of living have been focused on expenditure, per capita Gross Domestic Product, wages, income, income distribution and poverty, the literature has recognized that sometimes such measures do not allow for real comparisons among countries, because of the difficulties that arise when using monetary variables (i.e. purchasing power parity) and their dependence on income distribution, (i.e. Poverty gap, Human Development Index and Gini Index). Other theoretical approaches, such as Sen (1987, 1987b), state that standard of living is not the same as opulence, even though it is influenced by it. In this sense, it is different from welfare and well-being in the traditional form.

In contrast with traditional literature, we do not use the BMI as a continuous variable. Here, we are interested in assessing how far the people are from the normal BMI range and to explain what determines the probability of being in a normal range or being out of it. We do that by evaluating the relation between the BMI and some socioeconomic variables such as: educational level, socioeconomic stratification, or wealth index, among others. In particular, although there are distinct causes for low or high values in the BMI, it is clear that both are associated to worse health and physical living conditions.

We think our approach is important for several reasons: First of all, it undertakes BMI extreme values as a synonym of bad standard of living which reformulates the continuous policy emphasis in obese people and follows other similar studies as Contoyannis and Wildman (2007). Second, we include health perception among the explanatory variables in order to capture the relationship between actual BMI and self-reported health status. This is a way to evaluate the physiological impact of BMI on the individual. Among the studies that undertake this phenomenon, we find some in this area as Etile (2007) who links ideal body weight and social norms, and Atlantis and Baker (2008) that review epidemiological studies of obesity effects on depression. Other studies about this phenomenon are: Carr 
and Friedman (2005), Paquette and Raine (2004), Prentice and Jebb (2001) Williamson et al (1993), Cash and Brown (1989) and Cash and Green (1986), among others. Third, we use two different measures of BMI. on the one hand, we use the traditional and standard international ranges of obesity. On the other hand, we propose a relative measure that takes into account the distribution of BMI among the people in the sample. In this sense, Ideal BMI as an indicator of individual aspirations and average BMI in each social group could reflect a proxy of how the individual believes she/he ought to behave, given one's group membership (see Etile (2007) for details).

We also think Colombia is an interesting study case because geographical and climatic conditions generate many differences in feeding and work habits, and government has made considerable efforts in public health in order to stimulate healthy habits (i.e. sports practicing sports and intake of food). It is also important to note that Colombia is a developing country with relatively high poverty levels.

The document is subdivided as follows. The next section briefly summarizes some of the main approaches that link standard of living and health theories. The third section shows the summary descriptive statistics, and the next is dedicated to the model. Finally, we present some policy highlights.

\section{Standard of Living and Health.}

There are many approaches to the standard of living concept. Some of them are focused in economic terms and other are linked to a wider concepts. When Sen (1987) states, “...you could be well off, without being well, you could be well without being able to lead the life

you wanted, you can have this life without being happy and so on", the idea of standard of living change its meaning from a perspective of opulence to a situation in which feelings and desires matter. Sen (1987)'s definition of standard of living includes the capabilities and functionings that the individual can do. A functioning is an achievement, whereas capability is the ability to achieve. Standard of living includes what the people can be or do with their goods and it lets us understand the link among goods and living conditions. This assumption lets us to link standard of living with non-monetary things such as health concepts (i.e. height, weight, illness among others). However, there are some measures traditionally used in economics as the Human Development Index (HDI) that includes both types of variables (income, life expectancy, and education). Other measures as 
proposed in Gamboa and Guerra (2006) include information from self-perception of household's living conditions, physical and human capital variables, and demographic aspects. Kahneman and Krueger (2006) provide a detailed study of subjective measures of well-being, happiness and self reported utility and their evolution in the literature. From their approach we can extract the importance of surveys with questions about individual preferences. Acceptance of self-reported measures of well-being could influence economics. As they say, subjective measures of well-being would enable welfare analysis in a more direct way. Focusing on subjective well-being could lead to a shift in emphasis from the importance of income in determining a person's well-being toward the importance of his or her rank in society. They say life satisfaction is relatively stable, but it can be affected by changes in circumstances.

In contrast, we can find several studies that link anthropometric conditions with standard of living. Steckel (1995) and Fogel (1989) associate standard of living with the stature of the people and their respective studies confirm the utility of anthropometric indicators in the analysis of quality of life. According to Steckel (1995), stature is an appropriate indicator of health status (indirectly) that reflects not only genetic but also environmental conditions and it can even give information about history of net nutrition. Besides this, it is highly correlated with production -a more common measure of standard of living - and it allows us to analyze the relation between nutrition and productivity since height depends on factors such as diet, medical care and exercise during childhood, among others, which may be influenced by socioeconomic factors. Nubé et al (1998) and Meisel and Vega (2006) say that measures such as the Body Mass Index, nutrition, literacy rates, life expectancy, morbidity and access to drinking water, are useful proxies to evaluate standard of living. According to Nubé et al (1998) some studies have found that in developing countries the BMI for adults is positively related to other measures of development as income or expenditure. Specifically, in Ghana there is evidence that confirms that the BMI can be used as an indicator of standard of living. Nubé et al (1998) found that the direct relationship between BMI and the characteristics of households analyzed makes it possible to expect that differences in standard of living may be reflected on BMI. Although weight is also positively related to other indicators of standard of living, height is not considered an appropriate proxy due to genetic conditions. As a result, the BMI is a better way to approach it because it includes both. 
Ford et al (2001) found that people who have a BMI with extreme values are those individuals with an impaired quality of life, and specifically they find a higher risk of being unhealthy in people with the lowest scores of BMI. They use variables related to activity limitation and mental and physical health to evaluate the standard of living. This study goes further, comparing with other documents, because the negative association between overweight and obesity and Health-Related Quality of Life (HRQL) is corroborated for males and females from all the age groups and ethnicities.

From the BMI point of view, we can distinguish two distinct subsets: people with lower BMI and people with higher BMI. In low-income countries, Nubé et al (1998) state that there is an important number of individuals that have a BMI under the scores considered as normal (18.5-24.9), which is considered as Chronic Energy Deficiency (CED). In the opposite side, the average of BMI among adults is higher in developed countries. Nevertheless, obesity is almost as undesirable as CED; although being either above or under certain range of BMI could be considered undesirable in terms of quality of life, the dimension in standard of living is different. Energy deficiency is associated with a higher vulnerability to illness, lower productivity, increased mortality, and it has special negative effects on pregnant women since it enhances the risk of low birth weight with the respective intergenerational health and malnourished problems (Shaheen and Lindholm, [2006]).

In a recent essay, Steckel (2008), examines valuable contributions of biological measures to understand levels and changes in human well-being (life expectancy, morbidity, stature, and certain features of skeletal remains). These aspects are final desires, no means, to get other things. In this approach health is so important to their quality of life that most researches refer to them as "biological standard of living."

On the other hand, high levels of BMI are not healthy, because they are related to heart attacks, some types of cancer, diabetes, among other illnesses. Obese people have different problems when compared to very thin people, for example in terms of mobility, selfesteem, or the reasons (including the socioeconomic ones) for being out of the normal BMI range. Nevertheless, these differences are manifested not only among the different groups (very thin or very fat people), but also inside one group. In this sense, Kolotkin et al (2002) analyzes the impact of overweight in the standard of living using variables like physical function, sexual life, and public distress, among others, and they conclude that 
there are important differences in standard of living among obese people. He finds that HRQL of people with high scores of BMI is statistically and significantly different. The worst HRQL, according to this paper, is for the group of people enrolled in treatments for losing weight, but even for these people, HRQL varies depending on the way people use for losing weight (gastric bypass, clinical trials...).

As it can be seen, considering that the standard of living is the same for people being in opposite sides of the scale of BMI (very thin or very fat), could be as questionable as considering that people in the same range of BMI have the same standard of living. Nevertheless, for the purpose of this paper the conditions that explain a too low or too high BMI, although different, are in both cases undesirable for the individuals. In a similar way, Waaler (1984) found that in the case of Norway, men who have a BMI under 22 or above 28, have higher death rates. Other studies also confirm the negative association between obesity and quality of life (Han et al [1998], Lean et al [1998, 1999], Ford et al [2001]). In summary, having a BMI out of the normal range could be linked to a lower standard of living and it is a public health concern since it can bring some intergenerational effects.

In the case of overweight, Delva et al (2007) affirm that some lifestyle behaviors affect the BMI, and also affect standard of living (exercising, consumption of fruits and vegetables and little time watching television). He found that these reduce the risk of overweight (being at or above de $85^{\text {th }}$ percentile of age and gender adjusted BMI). Besides, Delva et al (2007) mention that the effects of television could be stronger for people from low socioeconomic status and ethnic minorities because, in general, they spend more time watching television than people from higher status groups. This illustrates the fact that lifestyle behaviors and income have consequences on health variables such as BMI and hence on the standard of living. In general, socioeconomic status and health disorders may be correlated; in the case of obesity, Sobal and Stunkard (1989) and Delva et al (2007) find a negative correlation between overweight and socioeconomic status.

The relationship among BMI and personal habits has been studied in several works. Some examples are Jeffery and French (1997) for the impact of fast food on obesity, Garrow and Summerbell (1995) analyze the effect of exercise on body composition with or without dieting, Fernald (2007) who explores the effect of beverage consumption in rural (low- 
income) Mexican population. Shannon et al (1991), Risse (1991), and Tucker and Friedman (1989), among others, relate television use and weight disorders and they find a positive relationship between these variables.

On the other hand, Sobal and Stunkard (1989) find a negative relationship between socioeconomic status and obesity or overweight for women in developed countries, but the relation seems to be inexistent in the case of children and men. For developing countries the relation is positive for both men and women. It is common to associate obesity with low income for the kind of food people intake. On the other side, people with high income levels have types of work that could be related to obesity. As can be seen, there are different aspects that explain why BMI is below or above the 'Normal' range and the association of BMI and SES is not definitive. In studies such as Sarlio-Lähteenkorva et al (2004), obesity is associated with a clear income disadvantage, particularly among women with higher socioeconomic status.

The relationship between weight disorders (obesity or underweight) and SES could be also analyzed by using the literature that attempts to explain the correlation between health and education by means of education as a SES indicator. This relation could be interpreted in two different ways. On the one hand, a better education allows people to be healthier, but the relation in the opposite direction could be true since better health can enhance the performance in school. On the other hand, Mac Innis (2006) proposes that variables such as genetics could affect both health and education in the same direction. He studies the relation between education and obesity and concludes that college completion reduces the probability of overweight and other disorders in the case of Vietnam. According to Mac Innis (2006) the impact of college education on health (smoking, obesity, among others) can operate through the relation with productivity (healthier people are more productive) and income (wealthier people can afford a better protection).

Besides weight, we can study the relationship between stature and socioeconomic variables as proposed by Steckel (1995) and Fogel (1989). Nevertheless -at the individual level- the height-income relation may not be linear because although poverty is importantly related to malnutrition (and the respective consequences on stature), the fact of having been brought up in a wealthier family does not ensure the possibility of being a "giant" (Steckel [1995]). He found that in the case of United States, the link between stature and per capita income 
should incorporate things such as income or wealth distribution and diet or nutritional requirements when we are interested in height as indicator of standard of living.

For the Colombian case, Meisel and Vega (2004) analyze the evolution of height between 1910 and 1984 and they found an improvement in the biological standard of living -that is one of the aspects of quality of life as a whole-. They not only found that stature has significantly increased for both men and women, for all socioeconomic status and all the Colombian regions, but also that this progress has been accompanied by an important reduction in dispersion. They find $\beta$-convergence that allows affirming that regions with less stature at the beginning of the period were those which reported the highest growth rates $^{1}$. This increase in height of Colombians could be explained because of the better performance in health, nutrition and labour conditions. Studying stature at an inter-regional level, Meisel and Vega (2004) report that average height is explained by both racial composition and per capita GDP. They conclude that quality of life has increased in this period and it has also become more equitable, thanks to the reduction in dispersion.

\section{Data}

WHO (1995) states that when the index is associated to differences in the society, or is affected by socioeconomic factors (even factors such as health or nutrition), it could be used either as a socioeconomic or equity indicator. Consequently, the index can be seen as a proxy of socioeconomic status. Formally our measure of BMI is given by BMI $=$ weight $[\mathrm{Kg}] /$ height $[\mathrm{mts}]^{2}$ ). Data about BMI are no frequent in Colombia, as in other developing countries. Our data base is the Demography and Health National Survey (Encuesta Nacional de Demografía y Salud), -DHNS hereafter-, which is carried out each five years, but the measurement of BMI was done in 2005 for first time.

DHNS includes information about socioeconomic conditions and anthropometry of the population. We do not take into account all the observations due to the following reasons. First, we exclude people under 15 years old because the anthropometric measures such as height and weight could depend on the stage of growth in childhood. Second, we also discard those observations with a BMI scores out of the interval 13-50 (more than 70 cases) that could be considered either outliers or information containing mistakes (for

${ }^{1}$ In economic growth $\beta$-convergence refers to the fact that poor economies have higher growth rates than richer ones. 
instance, errors at the moment of the interview) ${ }^{2}$. Finally, we take out of the sample people without BMI information, pregnant women and people whose information about education is not available. After that, our database is about 72.239 observations.

Table 1.

Distribution of BMI in Colombia 2005

\begin{tabular}{lcccc}
\hline & BMI & Female & Male & Total \\
\hline Severe Thinness & $<16$ & 0,38 & 0,49 & 0,42 \\
Moderate Thinness & $16-17$ & 0,85 & 1,20 & 0,98 \\
Underweight & $17-18,5$ & 3,68 & 4,95 & 4,16 \\
Normal & $18,5-25$ & 48,87 & 57,71 & 52,24 \\
Overweight & $25-30$ & 31,05 & 27,78 & 29,80 \\
Obese Level-I & $31-35$ & 14,30 & 7,72 & 11,79 \\
Obese Level-II & $36-40$ & 0,86 & 0,16 & 0,59 \\
\hline Total & \multicolumn{5}{c}{$38 \%$} & $62 \%$ & 100 \\
\hline
\end{tabular}

Source: DHS 2005, Colombia.

As we can see, there are more females with higher scores in BMI than men, and we found that about 50 percent of the people are out of the normal range (Table 1). The sample consists of $62 \%$ women; three out of four observations come from urban areas and almost $6 \%$ are from Bogotá. The fact of having an important difference between the observations of men and women is not associated to sample design and it is explained by the purpose of the survey which seeks to gather specific variables in the case of women. As can be seen, higher IMC is more frequent in women.

In the case of the variables used to obtain the BMI, neither weight nor stature has a normal distribution (Table 2). This can be explained because of the different factors (such as genetics, nutrition, physical activity or exercise) that can affect these variables in different directions (enhancing or reducing weight) depending, for instance, on age. After certain age, the index only changes due to weight. Nevertheless, in the case of the height distribution, mean and median coincide. The information suggests that men are taller than women and are expected to have a higher weight, on average.

${ }^{2}$ For people whose BMI is less than 13 , we find an average height of $1.6 \mathrm{~m}$ and an average weight of $18 \mathrm{~kg}$. In the case of people with a BMI above 50, the averages are $1.34 \mathrm{~m}$ and $80.6 \mathrm{~kg}$ respectively. 
Table 2.

Sample Characteristics of Weight (Kgms) and Height (M.)

\begin{tabular}{lcccccccccc}
\hline & \multicolumn{3}{c}{ Women } & \multicolumn{3}{c}{ Men } & \multicolumn{3}{c}{ Total } \\
\hline Mean & Weight & Height & BMI & Weight & Height & BMI & Weight & Height & BMI \\
Standard Deviation & 60.46 & 1.55 & 25.23 & 67.15 & 1.67 & 24.00 & 63.07 & 1.6 & 24.75 \\
Median & 12.14 & 0.06 & 4.88 & 13.1 & 0.07 & 4.21 & 12.94 & 0.09 & 4.67 \\
Skewness & 58.8 & 1.55 & 24.58 & 65.4 & 1.67 & 23.44 & 61.4 & 1.59 & 24.12 \\
Kurtosis & 0.86 & -0.04 & 0.81 & 0.76 & -0.16 & 0.79 & 0.8 & 0.22 & 0.84 \\
\hline
\end{tabular}

Source: DHS 2005, Colombia.

We also find that the mean of BMI in Colombia is in the normal range, although it is located near the upper limit of this range $(24,75)$. Nevertheless, there is a statistical difference between women and men. The standard deviation of this indicator suggests that there is more homogeneity in the group of men (the standard deviation is lower) than in the group of women.

There seems to be no important differences in the distribution of BMI by regions of residence, although in the case of Bogota the population is more homogeneous and we find less people in the extreme cases of BMI categories. People from urban areas have, on average, a higher score of BMI (24.941) compared to people from rural areas (24.28). This situation may be a consequence of factors such as job and nutrition, which are very specific in each area. Rural inhabitants in Colombia normally have jobs that are intensive in physical effort and they usually have a diet rich in carbohydrates; the opposite is true in the case of people who live in urban areas.

Even if people are in the extreme categories of BMI, they may consider themselves as healthy (Figure 1). Meanwhile, the 75 percent of people who declare having an excellent or good health have a BMI of 27 or less and in the case of people that feel unhealthy, this value is 28. It is also found that the group of people who feel healthy is more homogeneous (SD of BMI is 4,5) than the group of people who states they are not very healthy $(\mathrm{SD}=5)$. We can conclude that there is a direct relationship between self-reported health status and BMI. 
Figure 1.

BMI and Self-reported health status

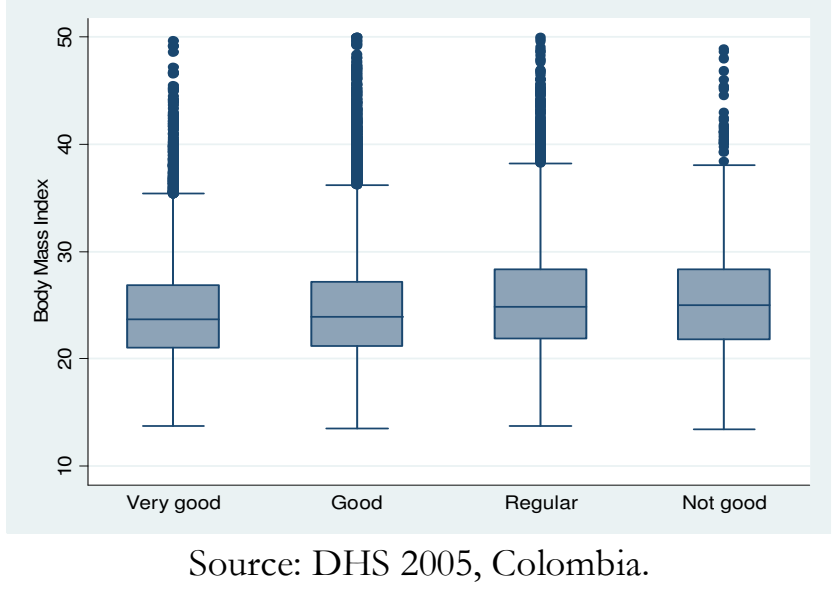

It is interesting to note that the distribution of BMI by age exhibits similar patterns of other international findings. In general, mean tends to increase as age does and women and men have very similar distributions. When we take into account the educative level and the area of residence at the same time, we find similar patterns between urban and rural people. 
Figure 2.

\section{BMI Distribution by Area}

Colombia 2005

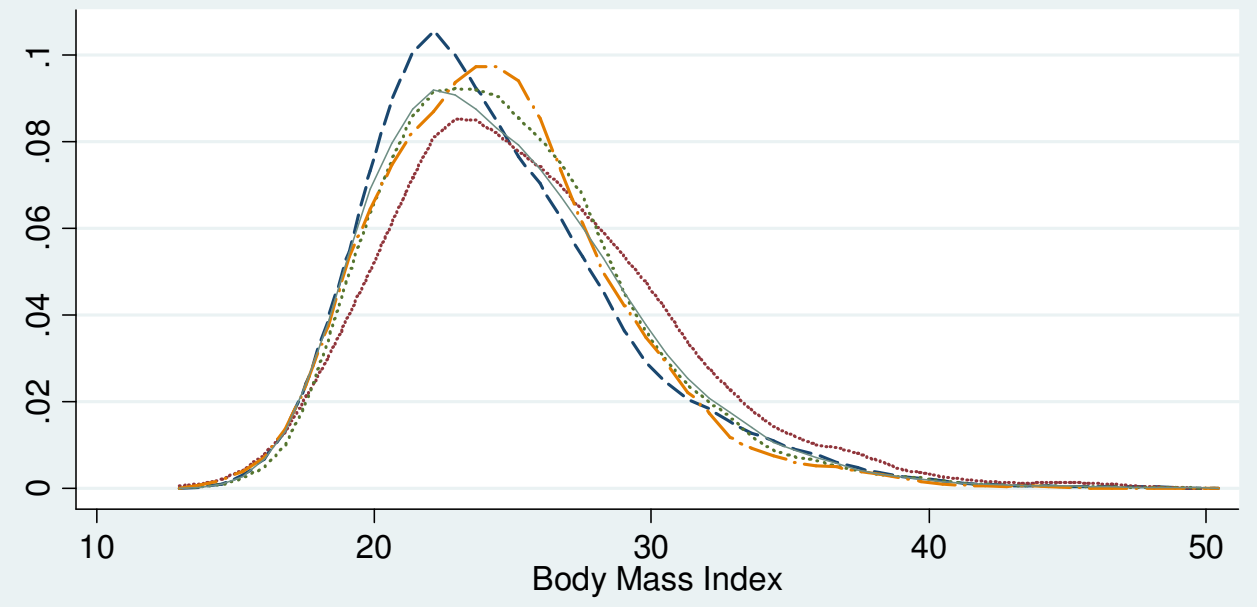

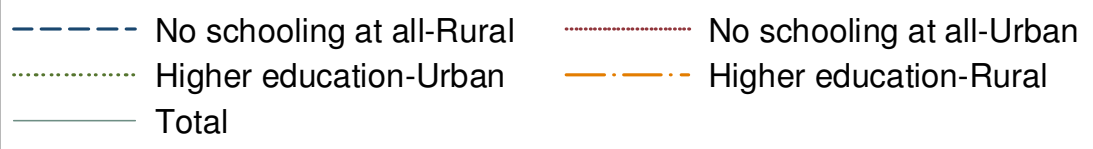

Source: DHS 2005, Colombia.

Figure 3.

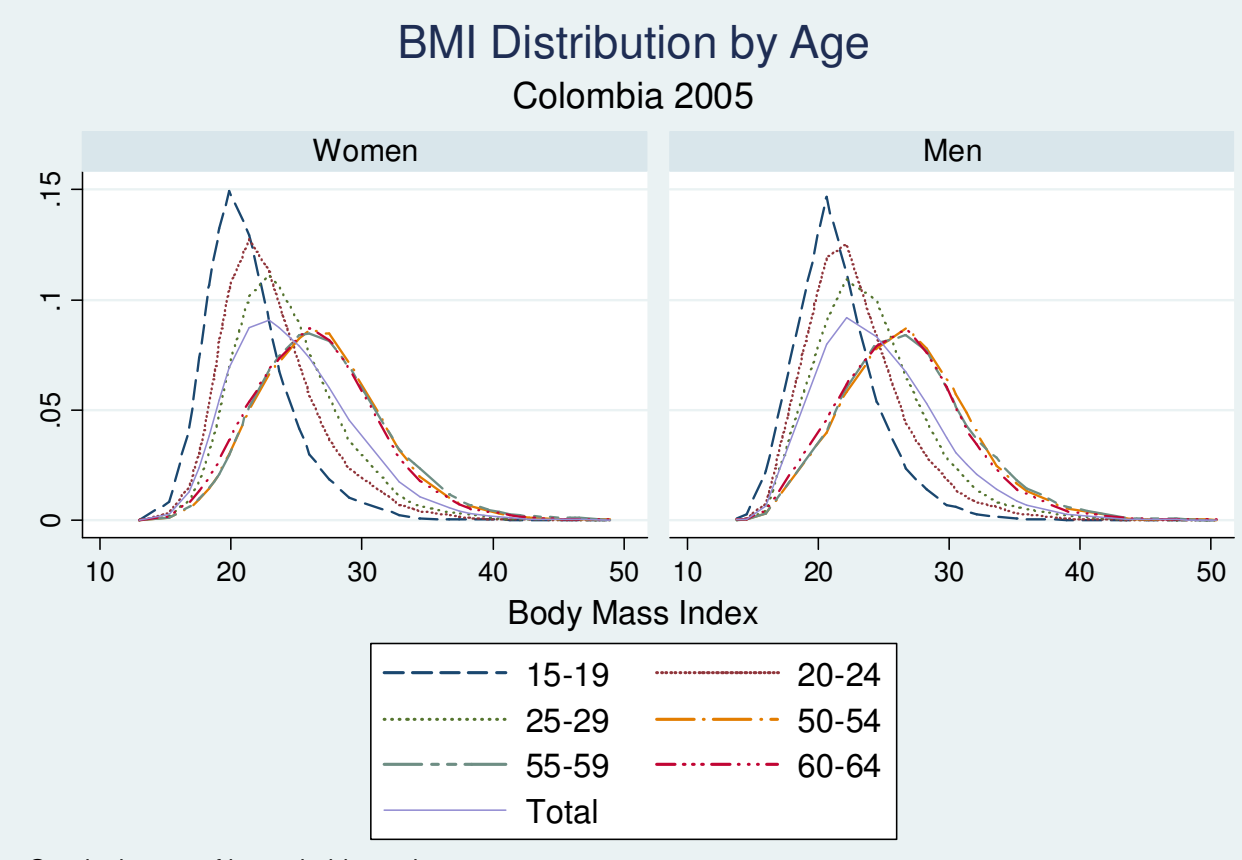

Graphs by sex of household member

Source: DHS 2005, Colombia. 


\section{The Model}

As we mentioned above, our approach depends on two distinct definitions of our dependent variable. One of them is normative because it takes into account the standardized BMI ranges in order to sort the population, whereas the other is relative to the actual distribution of the people. In the former, we define our categorical variable $y_{1}$ as follows:

$$
y_{1}=\left\{\begin{array}{l}
0 \quad \text { if } 18.5<B M I<25 \\
1 \quad \text { if } B M I \in(17,18.5) \text { or }(25,30) \\
2 \quad \text { if } B M I \in(16, \quad 17) \text { or }(30,39) \\
3 \quad \text { if } B M I<16 \text { or } B M I>39
\end{array}\right.
$$

In this specification, we valuate in the same way people who are under or above the normal range, but it includes more categories for taking into account how far from normal range they are. This variable lets us establish how far an individual is from the 'normal' range, but it gives the same treatment to observations above or below that range. Normal BMI is given a zero value, people with overweight and thinness gets a 1 and so on. Then, our marginal coefficients can be read as the probability of being in each of the variable levels.

The second specification of the dependent variable is related to the distribution of the people around the index. In this sense, our interest is in assessing the differences with respect to the mean in the population. The variable $y_{2}$ is defined as:

$$
y_{2}=\left\{\begin{array}{l}
0 \text { if } B M I \in(B \overline{M I}-\sigma, B \overline{M I}+\sigma) \\
1 \text { if } B M I \in(B \overline{M I}-2 \sigma, B \overline{M I}-\sigma) \cup(B \overline{M I}+\sigma, B \overline{M I}+2 \sigma) \\
2 \text { if } B M I \in(B \overline{M I}-3 \sigma, B \overline{M I}-2 \sigma) \cup(B \overline{M I}+2 \sigma, B \overline{M I}+3 \sigma)
\end{array}\right.
$$

Where, $B \bar{M} I$ is the mean of the $B M I$ and $\sigma$ is its standard deviation in the sample. In contrast of $y 1$, this measure includes equally size ranges and it is calculated with respect to the sample distribution. As a result, people who are closer to the sample-mean get a value of zero, people with a BMI score between one and two standard deviations of the sample- 
mean, get a value of one and so on. Then, we have two different analyses: $y_{1}$ represents a normative measure and $\mathrm{y}_{2}$ is a relative measure.

As in other studies, control variables are limited to data availability. In our case, as explanatory variables we include gender, age (continuous or ranges), age squared (Age2) socioeconomic variables (educative level, wealth index, LCI, LCI squared (LCI2) and the stratification for public services), region, type of habitation place (urban or rural), selfreported health status, a dummy variable for taking into account any physical disability, and another dummy for their health security condition. We include the zone where individuals live (urban or rural) because of the particular differences in the type of work and food among both areas, which may influence the BMI and hence, the standard of living. Among the variables related to health status, we take account of difficulties for walking, since it is reasonable to think that a person with such disabilities may exercise less and consequently may have a higher BMI, associated to an impaired quality of life. As it can be seen, this set of variables lets us to include most of the information incorporated in previous studies.

The LCI is an indicator estimated by principal components, which includes information about household characteristics (wall and floor material among others), educational achievement, school attendance of children and overcrowding (according to the number of people and rooms for sleeping at home). It is not an asset index and it may give more information about the standard of living of families. The definition of the variables is as shown in the Table 3.

Table 3.

Explanatory Variables

\begin{tabular}{|c|c|c|c|}
\hline & variable & Definition & $\begin{array}{c}\text { Mean (Stdar. } \\
\text { Dev.) }\end{array}$ \\
\hline \multirow{3}{*}{$\begin{array}{l}\text { Socioeconomic } \\
\text { Characteristics }\end{array}$} & $\begin{array}{l}\text { Age } \\
\text { (Continuous) }\end{array}$ & Years & $34,3(13,65)$ \\
\hline & $\begin{array}{l}\text { Gender } \\
\text { (Dummy) }\end{array}$ & $0=$ Women, $1=$ Men. & 0,39 \\
\hline & $\begin{array}{l}\text { Residence (Region) } \\
\text { (Dummies) }\end{array}$ & $\begin{array}{l}\text { Dummies for each region: Atlantic, Eastern, Central, } \\
\text { Pacific and national Orinoquía. The reference is Bogotá. }\end{array}$ & \\
\hline
\end{tabular}




\begin{tabular}{|c|c|c|c|}
\hline & $\begin{array}{l}\text { Urban } \\
\text { (Dummy) }\end{array}$ & $0=$ Rural, $1=$ Urban. & 0,75 \\
\hline & $\begin{array}{l}\text { Educational Level } \\
\text { (Categorical or continuous in } \\
\text { completed years) }\end{array}$ & $\begin{array}{l}0=\text { No schooling at all; } 1=\text { Incomplete primary school; } \\
2=\text { Complete primary; } 3=\text { Incomplete Secondary school; } \\
4=\text { Complete Secondary complete; } 5=\text { Higher education; }\end{array}$ & \\
\hline & Asset Index (Categorical) & 1 = Poorest; 2 Poorer; 3 Middle; 4 Richer; 5 = Richest. & \\
\hline & $\begin{array}{l}\text { Living Conditions index } \\
\text { (Continuous) }\end{array}$ & From 0 (worst conditions) to 100 (the best condition). & $56,04(17,0)$ \\
\hline \multirow{4}{*}{$\begin{array}{l}\text { Variables } \\
\text { related to } \\
\text { health status }\end{array}$} & $\begin{array}{l}\text { Medical insurance in Health } \\
(\text { Dummy) }\end{array}$ & $0=$ No, $1=$ Yes. & 0,67 \\
\hline & $\begin{array}{l}\text { Self-Reported } \\
\text { Health Status (Categorical) }\end{array}$ & $1=$ Very good; $2=$ Good; 3=Regular; $4=$ Not good & \\
\hline & $\begin{array}{l}\text { Medical Consultation last } \\
\text { year (Dummy) }\end{array}$ & $0=$ Not or do not know; $1=$ Yes & 0,64 \\
\hline & $\begin{array}{l}\text { Difficulties for walking } \\
(\text { Dummy })\end{array}$ & $0=\mathrm{No} ; 1=\mathrm{Yes}$ & 0,01 \\
\hline
\end{tabular}

\section{Results}

Table 4 summarizes the distribution of the dependent variables that will be used in the different models estimated. In both specifications, zero categories may be considered as the normal or reference categories, since compared to the others, these categories reflect a better standard of living. Although almost all the people are concentrated in the group that has a better quality of life, there are individuals located in the worst extremes.

Table 4.

Distribution of the Dependent Variables

\begin{tabular}{ccccc}
\hline & \multicolumn{2}{c}{ Y1 } & \multicolumn{2}{c}{ Y2 } \\
\hline Categories* & Freq. & $\%$ & Freq. & $\%$ \\
\hline 0 & 37.369 & 51,7 & 50.358 & 69,7 \\
1 & 24.522 & 33,9 & 18.827 & 26,1 \\
2 & 9.603 & 13,3 & 3.054 & 4,2 \\
3 & 745 & 1,0 & - & - \\
Total & 72.239 & & 72.239 & \\
\hline
\end{tabular}

* Values that take a variable in the same category have different meanings. 
Source: DHS 2005, Colombia.

Due to we are working with a probabilistic model, we only show the marginal effects of the Ordered Probit ${ }^{3}$. Results show that, in general, marginal effects of the ordered probit estimation using $y_{1}$ (Table 5) and $y_{2}$ (Table 6) are analytically the same when we use either LCI or education as a proxy of socioeconomic conditions.

Besides these two specifications, the socioeconomic variable was approached by using an asset index -that ignores a more complete approach to the standard of living- or socioeconomic strata instead, and the main results were the same. In all the cases we incorporated to the model the educational achievement of the household head or his/her $\mathrm{BMI}$ and the main conclusions did not change.

Marginal effects indicate that being man or living either in Bogotá or in rural areas enhances the probability of being in the range of normal standard of living $(y=0)$ and reduces the probability of being out of it. In other words, the fact of being a woman or living in a different place increases the probability of having weight problems (either overweight or low weight). This result also shows us that gender differences are along the same lines than in other previous findings, as we have shown above. It is interesting to point out that rural people tend to exercise more (at work and to go there) than urban inhabitants, who have access to more transportation facilities and whose jobs demand less physical effort, in general. The result related to Bogotá could be a consequence of having more places for practicing sports, such as gyms, parks, spas, etc, compared to other cities.

There are non-linear and significant relationships between the BMI and the living conditions; the same is found in the relationship between BMI and years of education completed. This finding is important for health policy, because it implies that the standard of living varies among people with different education levels and hence, it does not have the same behavior across the life cycle since, for example, as people get more educated try to take more care about their health by either improving his nutritional habits or exercising. However, the sign and the size of the coefficients show that the impact of additional years

${ }^{3}$ For those interested in detailed results, please contact the authors. For more details about Ordered Probit Models see Wooldridge (2002). 
of schooling on the probability of being in any BMI category (as defined previously) is small. We test other specifications with dummies for identifying educative levels and the results are similar.

It is also important to state that increases in age reduce the probability of being in a normal range. From the health policy point of view it is one aspect to take into account in their preventive programs and in the diffusion of good nutritional habits starting from adolescence.

According to the variables associated with health status, marginal effects show that people who consider themselves healthy, individuals who have not had recent medical consultation, or people without problems for walking, have less probability of being out of the normal range of BMI. These results are robust to both specifications of the model. 
Table 5.

Marginal Effects - Y1

\begin{tabular}{|c|c|c|c|c|c|c|c|c|c|c|c|c|c|c|c|c|}
\hline & \multicolumn{8}{|c|}{ Marginal Effects Model 1} & \multicolumn{8}{|c|}{ Marginal Effects Model 2} \\
\hline & \multicolumn{2}{|c|}{0} & \multicolumn{2}{|c|}{1} & \multicolumn{2}{|c|}{2} & \multicolumn{2}{|c|}{3} & \multicolumn{2}{|c|}{0} & \multicolumn{2}{|c|}{1} & \multicolumn{2}{|c|}{2} & \multicolumn{2}{|c|}{3} \\
\hline & $\mathrm{dy} / \mathrm{dx}$ & $\mathrm{z}$ & $\mathrm{dy} / \mathrm{dx}$ & $\mathrm{z}$ & $\mathrm{dy} / \mathrm{dx}$ & Z & $\mathrm{dy} / \mathrm{dx}$ & z & $\mathrm{dy} / \mathrm{dx}$ & $\mathrm{z}$ & $\mathrm{dy} / \mathrm{dx}$ & $\mathrm{z}$ & $\mathrm{Dy} / \mathrm{dx}$ & $\mathrm{z}$ & $\mathrm{dy} / \mathrm{dx}$ & z \\
\hline Age (years) & -0.02 & -28.27 & 0.01 & 26.78 & 0.01 & 27.93 & 0.00 & 21.99 & -0.023 & -29.32 & 0.011 & 27.71 & 0.011 & 28.91 & 0.001 & 22.43 \\
\hline Age2 & 0.00 & 17.31 & 0.00 & -16.89 & 0.00 & -17.24 & $\begin{array}{c}-8.76 \mathrm{E}- \\
06\end{array}$ & -15.77 & 0.000 & 17.89 & 0.000 & -17.45 & 0.000 & -17.81 & 0.000 & -16.18 \\
\hline Gender & 0.08 & 23.04 & -0.04 & -22.11 & -0.04 & -23.13 & -0.0041 & -18.55 & 0.083 & 22.77 & -0.041 & -21.85 & -0.038 & -22.87 & -0.004 & -18.46 \\
\hline Atlantic & -0.05 & -5.73 & 0.02 & 5.92 & 0.02 & 5.58 & 0.0025 & 5.24 & -0.037 & -4.70 & 0.017 & 4.83 & 0.018 & 4.60 & 0.002 & 4.38 \\
\hline Eastern & -0.03 & -3.69 & 0.01 & 3.83 & 0.02 & 3.59 & 0.0017 & 3.41 & -0.031 & -3.61 & 0.014 & 3.75 & 0.015 & 3.52 & 0.002 & 3.34 \\
\hline Central & -0.01 & -1.77 & 0.01 & 1.80 & 0.01 & 1.76 & 0.0007 & 1.73 & -0.015 & -1.82 & 0.007 & 1.84 & 0.007 & 1.80 & 0.001 & 1.77 \\
\hline Pacific & -0.04 & -4.84 & 0.02 & 5.07 & 0.02 & 4.69 & 0.0022 & 4.40 & -0.039 & -4.69 & 0.018 & 4.90 & 0.019 & 4.54 & 0.002 & 4.27 \\
\hline Orinoquía & -0.07 & -8.17 & 0.03 & 8.95 & 0.03 & 7.68 & 0.0041 & 6.83 & -0.060 & -7.23 & 0.027 & 7.83 & 0.030 & 6.85 & 0.004 & 6.18 \\
\hline Urban & -0.02 & -5.05 & 0.01 & 4.96 & 0.01 & 5.12 & 0.0012 & 5.12 & -0.059 & -13.11 & 0.029 & 12.55 & 0.027 & 13.52 & 0.003 & 12.60 \\
\hline LCI & -0.01 & -14.42 & 0.00 & 14.25 & 0.00 & 14.37 & 0.0004 & 12.99 & - & - & - & - & - & - & - & - \\
\hline LCI2 & 0.00 & 12.62 & 0.00 & -12.52 & 0.00 & -12.59 & 0.0000 & -11.63 & - & - & - & - & - & - & - & - \\
\hline $\begin{array}{l}\text { Education } \\
\text { (years) }\end{array}$ & - & - & - & - & - & - & - & - & -0.010 & -7.08 & 0.005 & 7.06 & 0.005 & 7.08 & 0.001 & 6.91 \\
\hline Education2 & - & - & - & - & - & - & - & - & 0.001 & 7.52 & 0.000 & -7.50 & 0.000 & -7.51 & 0.000 & -7.30 \\
\hline $\begin{array}{l}\text { Medical } \\
\text { insurance in } \\
\text { Health }\end{array}$ & -0.02 & -5.91 & 0.01 & 5.84 & 0.01 & 5.97 & 0.0012 & 5.92 & -0.025 & -6.37 & 0.012 & 6.28 & 0.012 & 6.43 & 0.001 & 6.37 \\
\hline $\begin{array}{l}\text { Self-Reported } \\
\text { Health Status }\end{array}$ & -0.01 & -4.92 & 0.01 & 4.92 & 0.01 & 4.92 & 0.0007 & 4.82 & -0.010 & -3.43 & 0.005 & 3.43 & 0.005 & 3.42 & 0.001 & 3.39 \\
\hline $\begin{array}{l}\text { Medical } \\
\text { Consultation }\end{array}$ & -0.03 & -7.34 & 0.01 & 7.24 & 0.01 & 7.40 & 0.0014 & 7.27 & -0.033 & -8.58 & 0.016 & 8.44 & 0.015 & 8.66 & 0.002 & 8.43 \\
\hline $\begin{array}{l}\text { dificulties for } \\
\text { walking }\end{array}$ & -0.04 & -2.99 & 0.02 & 3.22 & 0.02 & 2.85 & 0.0024 & 2.64 & -0.045 & -3.17 & 0.020 & 3.43 & 0.022 & 3.02 & 0.003 & 2.78 \\
\hline
\end{tabular}


For the $\mathrm{y}_{2}$ case, conclusions are very similar to those found earlier. According to the definition of the dependent variable, the standard of living decreases with higher values of $\mathrm{y}_{2}$. The results indicate that the fact of being a man, living in Bogotá or in rural areas, increases the probability of enjoying a better quality of life (Table 6 ).

In both models -either the one that includes education or LCI - coefficients of marginal effects have the same sign; besides, signs of the categories 1 and 2 are always opposite to the sign of the category 0 . In the case of the variables that approach to socioeconomic conditions, the results show that both LCI and years of education have small coefficients that always have statistical significance and indicate that the effect of these variables is nonlinear.

Table 6.

Marginal Effects - Y2

\begin{tabular}{|c|c|c|c|c|c|c|c|c|c|c|c|c|}
\hline & & & \multicolumn{5}{|c|}{ Marginal Effects Model 1} & \multicolumn{5}{|c|}{ Marginal Effects Model 2} \\
\hline & \multicolumn{2}{|c|}{0} & \multicolumn{2}{|c|}{1} & \multicolumn{2}{|c|}{2} & \multicolumn{2}{|c|}{0} & \multicolumn{2}{|c|}{1} & \multicolumn{2}{|c|}{2} \\
\hline & $\mathrm{dy} / \mathrm{dx}$ & $\mathrm{z}$ & $\mathrm{dy} / \mathrm{dx}$ & $\mathrm{z}$ & $\mathrm{dy} / \mathrm{dx}$ & $\mathrm{z}$ & $\mathrm{dy} / \mathrm{dx}$ & $\mathrm{z}$ & $\mathrm{dy} / \mathrm{dx}$ & $\mathrm{z}$ & $\mathrm{dy} / \mathrm{dx}$ & $\mathrm{z}$ \\
\hline Age (years) & 0.015 & 22.29 & -0.0113 & -21.66 & -0.0038 & -22.83 & 0.015 & 21.27 & -0.0109 & -20.71 & -0.0036 & -21.79 \\
\hline Age2 & 0.000 & -22.95 & 0.0002 & 22.36 & 0.0001 & 23.22 & 0.000 & -21.94 & 0.0002 & 21.42 & 0.0001 & 22.21 \\
\hline Gender & 0.047 & 14.11 & -0.0358 & -14.08 & -0.0116 & -13.85 & 0.047 & 14.08 & -0.0358 & -14.05 & -0.0116 & -13.82 \\
\hline Atlantic & -0.087 & -10.22 & 0.0635 & 10.47 & 0.0232 & 9.47 & -0.086 & -10.14 & 0.0628 & 10.39 & 0.0229 & 9.40 \\
\hline Eastern & -0.041 & -4.43 & 0.0300 & 4.51 & 0.0107 & 4.20 & -0.042 & -4.52 & 0.0306 & 4.61 & 0.0109 & 4.29 \\
\hline Central & -0.049 & -5.74 & 0.0363 & 5.83 & 0.0128 & 5.47 & -0.050 & -5.83 & 0.0368 & 5.93 & 0.0130 & 5.56 \\
\hline Pacific & -0.049 & -5.40 & 0.0358 & 5.51 & 0.0128 & 5.09 & -0.049 & -5.47 & 0.0362 & 5.59 & 0.0130 & 5.15 \\
\hline Orinoquía & -0.047 & -5.11 & 0.0346 & 5.22 & 0.0125 & 4.80 & -0.046 & -4.98 & 0.0336 & 5.09 & 0.0121 & 4.69 \\
\hline Urban & -0.036 & -8.07 & 0.0276 & 7.98 & 0.0088 & 8.28 & -0.047 & -11.56 & 0.0358 & 11.39 & 0.0112 & 11.87 \\
\hline LCI & -0.003 & -6.62 & 0.0026 & 6.61 & 0.0009 & 6.59 & - & - & - & - & - & - \\
\hline LCI2 & 0.000 & 6.72 & 0.0000 & -6.72 & 0.0000 & -6.69 & - & - & - & - & - & - \\
\hline Education (years) & - & - & - & - & - & - & -0.005 & -3.71 & 0.0041 & 3.71 & 0.0014 & 3.70 \\
\hline Education2 & - & - & - & - & - & - & 0.000 & 5.17 & -0.0003 & -5.17 & -0.0001 & -5.17 \\
\hline $\begin{array}{l}\text { Medical insurance } \\
\text { in Health }\end{array}$ & -0.008 & -2.34 & 0.0064 & 2.33 & 0.0021 & 2.35 & -0.009 & -2.57 & 0.0070 & 2.57 & 0.0023 & 2.58 \\
\hline $\begin{array}{l}\text { Self-Reported } \\
\text { Health Status }\end{array}$ & -0.022 & -8.21 & 0.0168 & 8.20 & 0.0056 & 8.18 & -0.021 & -7.65 & 0.0156 & 7.64 & 0.0052 & 7.62 \\
\hline $\begin{array}{l}\text { Medical } \\
\text { Consultation }\end{array}$ & -0.007 & -1.97 & 0.0054 & 1.97 & 0.0018 & 1.97 & -0.009 & -2.45 & 0.0067 & 2.44 & 0.0022 & 2.45 \\
\hline $\begin{array}{l}\text { Difficulties for } \\
\text { walking }\end{array}$ & -0.061 & -4.11 & 0.0442 & 4.27 & 0.0169 & 3.72 & -0.062 & -4.18 & 0.0451 & 4.36 & 0.0173 & 3.78 \\
\hline
\end{tabular}

Source: DHS 2005, Colombia. 
In order to test the robustness and predictive level of these models, we estimated the mean probabilities and the out of the sample forecast probabilities. Table 7 shows the values that takes the dependent variable (in rows) and the average of the predicted values for all the observations in the correspondent category (in columns). For example, it means that on average, for the observations in the zero category of the first model $\left(\mathrm{y}_{1}\right)$ the model predicts a probability of $56 \%$ for being in that category, and probabilities of $32.1 \%, 11.1 \%$ and $0.8 \%$ for being in the first, second, and third categories. As can be seen, there could be an important relationship between the mean probabilities reported and the distribution of the frequencies of the variables (see Table 4). In each specification the highest mean probability corresponds to the predicted value for the zero category. It means that even for the group of observations that takes values different from zero (in either specification), the model leans to predict that those observations would be in the zero category.

Table 7.

Mean Probabilities

\begin{tabular}{|c|c|c|c|c|c|c|}
\hline & & & P0 & P1 & P2 & P3 \\
\hline \multirow{8}{*}{$\mathrm{Y} 1$} & \multirow{4}{*}{ Model 1} & 0 & 0.560 & 0.321 & 0.111 & 0.008 \\
\hline & & 1 & 0.485 & 0.356 & 0.146 & 0.013 \\
\hline & & 2 & 0.438 & 0.375 & 0.171 & 0.017 \\
\hline & & 3 & 0.498 & 0.342 & 0.146 & 0.014 \\
\hline & \multirow{4}{*}{ Model 2} & 0 & 0.559 & 0.321 & 0.112 & 0.008 \\
\hline & & 1 & 0.486 & 0.355 & 0.146 & 0.013 \\
\hline & & 2 & 0.439 & 0.374 & 0.170 & 0.016 \\
\hline & & 3 & 0.500 & 0.342 & 0.145 & 0.014 \\
\hline \multirow{6}{*}{ Y2 } & \multirow{3}{*}{ Model 1} & 0 & 0.702 & 0.257 & 0.041 & - \\
\hline & & 1 & 0.688 & 0.268 & 0.045 & - \\
\hline & & 2 & 0.679 & 0.274 & 0.047 & - \\
\hline & \multirow{3}{*}{ Model 2} & 0 & 0.702 & 0.257 & 0.041 & - \\
\hline & & 1 & 0.688 & 0.268 & 0.045 & - \\
\hline & & 2 & 0.679 & 0.273 & 0.047 & - \\
\hline
\end{tabular}

Source: DHS 2005, Colombia.

Finally, the last exercise consists of the analysis of the forecast outside the sample. In order to evaluate the power of prediction of the models in all the specifications, we follow a methodology in which we only use 90 percent of the sample (65.000 observations approximately) and estimate both models. Then, with the estimators obtained we predict the values over the 10 percent that were drawn forth. As a result, we get two probabilities and we take the difference between the mean probability obtained with the complete 
sample and the mean obtained with $10 \%$ of the observations. Then, we calculate the difference among these values. According to this methodology results in Table 8 show that the models have a good fitness outside the sample, because differences are insignificant.

Table 8.

Differences in probability between full and random reduced sample

\begin{tabular}{|c|c|c|c|c|c|c|}
\hline & & & P0 & P1 & P2 & P3 \\
\hline \multirow{8}{*}{$\mathrm{Y} 1$} & \multirow{4}{*}{ Model 1} & 0 & -0.002 & 0.001 & 0.001 & 0.000 \\
\hline & & 1 & 0.001 & -0.001 & -0.001 & 0.000 \\
\hline & & 2 & -0.001 & 0.000 & 0.000 & 0.000 \\
\hline & & 3 & -0.029 & 0.015 & 0.012 & 0.002 \\
\hline & \multirow{4}{*}{ Model 2} & 0 & -0.003 & 0.002 & 0.001 & 0.000 \\
\hline & & 1 & 0.001 & -0.001 & -0.001 & 0.000 \\
\hline & & 2 & 0.000 & 0.000 & 0.000 & 0.000 \\
\hline & & 3 & -0.023 & 0.012 & 0.000 & 0.001 \\
\hline \multirow{6}{*}{$\mathrm{Y} 2$} & \multirow{3}{*}{ Model 1} & 0 & 0.001 & -0.001 & 0.000 & - \\
\hline & & 1 & 0.001 & -0.001 & 0.000 & - \\
\hline & & 2 & 0.001 & 0.000 & 0.000 & - \\
\hline & \multirow{3}{*}{ Model 2} & 0 & 0.000 & 0.000 & 0.000 & - \\
\hline & & 1 & 0.000 & 0.000 & 0.000 & - \\
\hline & & 2 & 0.001 & -0.001 & 0.000 & - \\
\hline
\end{tabular}

Source: DHS 2005, Colombia.

\section{Concluding remarks}

The exercise proposed in this document sheds some light on the relationship between BMI and standard of living in Colombia. First, socioeconomic status is a significant determinant of quality of life when the standard of living is proxied by the BMI for all the specifications and its forecast capacity is robust. The evidence presented, confirms that there are nonlinear relationships between the variable that approaches the quality of life (BMI) and age and socioeconomic status.

Second, assuming that too high or too low scores of BMI do not reflect ideal conditions of life, estimations confirm that the fact of living in Bogotá -capital city-, in rural areas, or being a man is associated with a better standard of living (i.e. there is a higher probability for the population, to be in a normal range of quality of life). In the case of women, the association with low weight could be explained because of the social pressures that may particularly affect this population. In the case of overweight, the positive association 
between being woman and having a BMI out of the one considered as normal can be the consequence of the important differences in height by gender. For the sample analyzed there is a difference of 5 centimeters in the stature of men and women and if there are no important differences in diet, we could expect women to weigh more than men.

A health policy that seeks the reduction of weight problems among people should be focused on women, at least in the short run. This population is especially important since weight problems in pregnant women can have intergenerational consequences. Moreover, weight problems among women who have been pregnant are common, since many of them cannot return to their pre-pregnancy weight. An externality of this type of policy is the indirect effect on their children habits, (See Price et al, (2000) and Cole et al(2008), for details).

Besides, health policy ought to take account of the differences in nutrition habits between rural and urban areas, which may be the cause of the fact that people living in urban areas have a higher probability of being in an upper range of BMI, and hence, of having an impaired quality of life, compared to individuals in rural areas. In order to achieve an improvement in the standard of living by means of an advance in BMI indicators, health policy makers would need to encourage healthier nutrition and exercise habits among the population. Two examples of these policies are in Bogota: Bogota is a leader city in the construction of more than $100 \mathrm{~km}$ of ways specially designed for biking, and it also uses to have some of its main streets for walking, skating and biking on Sundays and holydays, which are known as "ciclovias".

One important aspect for health policy is the direct relationship between BMI and age. This is one task for policy makers because increases in IMC are strongly related to heart attacks and other health problems. Taking into account the costs generated by health problems associated with weight -even in developed countries-, and the deaths caused by such motives, it is really important to give a central role in health policy to programs focused on forming adequate nutrition and exercise habits among children. During the last decades, some increasing concerns over excessive weight and fashion trends have augmented the amount of people with anorexia and bulimia. Then, it is important to give the same attention to those extreme cases and focus efforts in vulnerable population. 


\section{References}

Atlantis E., and Baker M. (2008) Obesity effects on depression: systematic review of epidemiological studies International Journal of Obesity 32, 881-891

Burke MA, Heiland F. (2007). Social dynamics of obesity. Economic Inquiry): 45(3) 571 591

Carr D, Friedman M. 2005. Is obesity stigmatizing? Body weight, perceived discrimination and psychological wellbeing in the United States. Journal of Health and Social Behavior 46: 244-259.

Cash TF, Brown TA. (1989). Gender and body images: stereotypes and realities. Sex Roles 21: $361-373$.

Cash TF, Green GK. (1986). Body weight and body image among college women: perception, cognition, and affect. Journal of Personality Assessment 50: 290-301.

Cole T, C. Power, and G. Moore(2008) Intergenerational obesity involves both the father and the mother American Journal of Clinical Nutrition, May 1, ; 87(5): 1535 - 1536.

Contoyannis P., J. Wildman (2007). Using relative distributions to investigate the body mass index in England and Canada, Health Economics. 16 (9): 929 - 944

Delva J, Johnston L, O’Malley, P (2007) The Epidemiology of overweight and Related Lifestyle behaviors, Ratial/Ethnic and Socioeconomic Status Differences Among American Youth. American Journal of Preventive Medicine 33(4): 178-186.

Etile, F. (2007) Social Norms, Ideal Body Weight and Food Attitudes. Health Economics 16: 945-966

Fernald L (2007) Socio-economic status and body mass index in low-income Mexican Adults. Social Science \& Medicine 64: 2030-2042.

Fogel R (1989) Nutrition and the Decline in Mortality Since 1700: Some Preliminary Findings. Long-Term Factors in American Economic Growth. National Bureau of Economic Research 1402.

Ford E, Moriarty D, Zack M, Mokdad A, Chapman, D (2001) Self-reported Body Mass Index and Health-Related Quality of Life: findings from the Behavioral Risk Factor Surveillance System. Obesity Research 9(1):21-31.

Gamboa L.F., Guerra J (2006) Una Evaluación Estática y Dinámica de los Cambios en Calidad de vida en Colombia durante 1997-2003. Revista de Economía del Rosario 9(2):125-159. 
Garrow J, Summerbell C. (1995) Meta-analysis: effect of exercise, with or without dieting, on the body composition of overweight subjects. European Journal Clinic Nutrition; 49: 1-10.

Han T, Tijhuis M., Lean M, Seidell J (1998) Quality of life in relation to overweight and body fat distribution. American Journal Public Health 88(12):1814-1820.

Kahneman D and A.Krueger (2006). Developments in the Measurement of Subjective Wellbeing. Journal of Economic Perspectives. 20(19): 3-24

Kolotkin R, Crosby R, Williams R (2002) Health-Related Quality of Life Varies among Obese Subgroups. Obesity Research, 10(8):748-756.

Lean M, Han T, Seidell J (1998) Impairment of health and quality of life in people with large waist circumference. Lancet 351(9106):853-856.

Lean M, Han T, Seidell J (1999) Impairment of health and quality of life using new US Federal guidelines for the identification of obesity. Archives of International Medicine 159(8):837-843.

McInnis B (2006) The Long-Term Effect of College Education on Morbidities: New evidence from the Pre-Lottery Vietnam Draft. Draft presented at the NBER Summer Institute.

Meisel A, Vega M (2004) La estatura de los colombianos: Un ensayo de antropometría histórica, 1910-2002. Documentos de Trabajo sobre Economía Regional, Banco de la República (Cartagena).

Meisel A, Vega M (2006). Los orígenes de la antropometría histórica y su estado actual. Cuadernos de historia económica y empresarial, Banco de la República (Cartagena).

Nubé M, Asenso-Okyere W, Van den Boom, G (1998) Body Mass Index as indicator of standard of living in developing countries. European Journal of Clinical Nutrition, 52(2):136-144.

Paquette M-C, Raine K. (2004). Sociocultural context of women's body image. Social Science and Medicine 59: 1047-1058.

Price R., D. Reed and N. Guido. (2000) Resemblance for Body Mass Index in Families of Obese African American and European American Women. Obesity Research 8, 360366

Prentice A.M, Jebb S.A. (2001). Beyond body mass index. Obesity Reviews 2: 141-147.

Rissel CE. Overweight and television watching. Australian Journal of Public Health. 1991;15:147-150. 
Sarlio-Lähteenkorva S., K. Silventoinen, and E. Lahelma,(2004) Relative Weight and Income at Different Levels of Socioeconomic Status. American Journal of Public Health.; 94: 468-472

Sen A (1987) The Standard of Living: Lecture I, Concepts and Critics, en Hawthorn Geoffrey. Cambridge University Press.

Sen A (1987b). The Standard of Living: Lecture II, Lives and Capabilities, en Hawthorn Geoffrey. Cambridge University Press.

Shaheen R, Lindholm, L (2006) Quality of life among pregnant women with chronic energy deficiency in rural Bangladesh. Health Policy, 78(2-3):128-134.

Shannon B, Peacock J, Brown MJ. Body fatness, television viewing and calorie-intake of a sample of Pennsylvania sixth grade children.Journal of Nutrition Education. 1991;23:262-268.

Slottje D (1991). Measuring the quality of life across countries. Review of Economics and Statistics 73(4):684-693.

Sobal J, Stunkard A (1989) Socioeconomic status and obesity: A review of the literature. Psychopharmacology Bulletin 105(2):260-275

Steckel R. (2008). Biological Measures of Standard of Living. Journal of Economic Perspectives. 22(3), 129-152

Steckel R (1995) Stature \& the Standard of living. Journal of Economic Literature 33(4):1903-1940.

Sugden R (1993) Welfare, resources, and capabilities: a review of inequality reexamined by Amartya Sen. Journal of Economic Literature 31(4):1947-1962.

Tucker LA, Friedman GM. Television viewing and obesity in adult males. American Journal of Public Health. 1989;79:516-518.

Waaler H (1984) Height, Weight, and Mortality: The Norwegian Experience. Acta Medica Scandinavica 679:1-56.

Williamson D, Gleaves D, Watkins P, Schlundt D. (1993). Validation of self-ideal body size discrepancy as a measure of body dissatisfaction. Journal of Psychopathology and Behavioral Assessment 15: 57-68.

Wooldridge J (2002) Econometric analysis of Cross Section and Panel Data.The Mit Press.

World Health Organization, WHO (1995) Physical Status: The Use and Interpretations of Anthropometry. WHO Technical Report Series 854. Geneva. 